\title{
Implemetasi Website SD Muhammadiyah 05 Karang Talun, Kabupaten Cilacap
}

\author{
Isa Bahroni $^{{ }^{*}}$, Andesita Prihantara ${ }^{2}$, Abdul Rohman Supriyono ${ }^{3}$ \\ 1,2Program Studi Teknik Informatika, Politeknik Negeri Cilacap, Indonesia \\ Email: ${ }^{1}$ bahroni37a@gmail.com, ${ }^{2}$ andz1203@ politeknikcilacap.ac.id, ${ }^{3}$ a.rohman.sy@pnc.ac.id
}

\section{INFORMASI ARTIKEL}

\section{Data artikel:}

Naskah masuk, 30 Desember 2020

Direvisi, 10 Januari 2021

Diiterima, 26 Januari 2021

\section{Kata Kunci:}

Implementation,

Website,

PPDB

\begin{abstract}
ABSTRAK
Abstract- SD Muhammadiyah 05 Cilacap was established in 1970 in the village of Lomanis Banyusrep South Cilacap, is an educational institution under the leadership of the Muhammadiyah branch of North Cilacap. The curriculum that is taught using the curriculum of the Cilacap Regency Education office has the function of preaching Islam to the community. SD Muhammadiyah 05 is named SD Mulia which is an educational organization that is fixing the information system so that it is easily accessible to the public and widely known by the public so that its activities can support its existence. Request for fast and accurate information at the time of PPDB (New Student Registration) using information and communication technology is very urgent. The Community Service Team created an android-based website to answer the problems faced at SD Mulia, with a system that can be accessed using smartphone media.
\end{abstract}
Abstrak- SD Muhammadiyah 05 Cilacap berdiri pada tahun 1970 di desa Lomanis Banyusrep Cilacap Selatan, adalah sebuah lembaga pendidikan dibawah binaan pimpinan cabang Muhammadiyah Cilacap Utara. Kurikulum yang diajarkan memakai kurikulum dinas Pedidikan Kabupaten Cilacap, mempunyai fungsi dakwah islamiyah kepada masyarakat. SD Muhammadiyah 05 diberi nama SD Mulia yang merupakan organisasi pendidikan yang sedang membenahi sistem informasi agar mudah dijangkau oleh kalangan masyarakat dan diketahui publik secara luas sehingga kegiatannya dapat menunjang eksistensinya. Permintaan Informasi cepat dan akurat pada saat pelaksanaan PPDB (Pendaftaran Peserta Didik Baru) dengan menggunakan teknologi informasi dan komunikasi sangat mendesak. Tim Pengabdian Kepada Masyarakat membuat website berbasis android untuk menjawab maslah-masalah yang dihadapi di SD Mulia, dengan sistem yang dapat diakses menggunan media smart phone.

\section{Korespondensi:}

\section{Isa Bahroni}

Program Studi Teknik Informatika, Politeknik Negeri Cilacap

J1. Dr. Soetomo No.1 Karangcengis, Sidakarya Cilacap, Indonesia 
Vol. 3, No.1, Februari 2021, pp. 24-30

p-ISSN: 2686-2301, e-ISSN: 2686-035X, DOI: 10.35970/madani.v1i1.532

\section{PENDAHULUAN}

Pendidikan merupakan faktor yang sangat penting dalam kehidupan dan perkembangan suatu negara, semakin baik dan kualitas proses pendidikan suatu bangsa maka akan berdampak positip dalam perkembangan negara tersebut, perkembangan dan majunya suatu negara dapat diukur dari tingkat kemajuan sistem pendidikan yang dipakai (Wanti \& Tripustikasari, 2019). Semakin mengerti pentingnya pendidikan maka akan semakin baik kualitas pendidikan di negara tersebut. Indonesia adalah negara berkembang, tentunya dalam segala aspek kehidupan terutama dalam dunia pendidikan. Namun pada keyataannya perkembangan saat ini tentang dunia pendidikan di Indonesia masih dapat dibilang ketinggalan dengan negera-negara tetangga, terutama dalam bidang pemerataan insfrastruktur pendidikan dari hulu sampai hilir.

SD Muhammadiyah 05 Cilacap berdiri tahun 1970 di desa Lomanis Banyusrep Cilacap Selatan, karena gusuran Pertamina pada tahun 1990 maka sekarang pindah di desa Karang Talun Cilacap Utara. Jumlah SD yang dibina oleh pimpinan cabang Muhammadiyah Cilacap Utara ada 3, sedangkan SD Muhammadiyah dalam binaan Pimpinan Daerah Muhammadiyah Kabupaten Cilacap semua ada 10 SD yang tersebar dibeberapa kabupaten Cilacap

Proses belajar mengajar mengikuti kurikulum pendidikan dibawah dinas pendidikan dan kebudayaan kabupaten Cilacap. Aktivitas sistem pendidikannya sampai dan pelaksanaan PPDB (Penerimaan Peserta Didik Baru) dalam menjaring anak didik baru masih menggunakan cara paper base, disampaikan dari mulut kemulut oleh setiap guru dan alumni, padahal di era digitalisasi sekarang ini kecepatan mengolah data dalam memperoleh informasi sangat diperlukan dalam dunia pendidikan. Hingga saat ini SD Mulia masih menggunakan brosur dan media sosial WA (WhatsApp) sebagai media publikasi kepada pihak luar. Banyak masyarakat yang keslitan dan mengeluh jika ingin mendapatkan informasi tentang kemajuan SD Mulia.

Proses Penerimaan Siswa Baru (PPDB) merupakan strategi langkah awal proses penyelenggaraan pendidikan baik tingkat dasar maupun perguruan tinggi. Berdasarkan Peraturan Menteri Pendidikan dan Kebudayaan nomor 44 Tahun 2019, BAB I Pasal 2. Tentang Penerimaan Peserta Didik Baru pada Taman Kanak-Kanak, Sekolah Dasar, Sekolah Menengah Pertama, Sekolah Menengah Atas dan Sekolah Menengah Kejuruan, PPDB dilakukan berdasarkan: nondiskriminatif, objektif, transparan, akuntabel, dan berkeadilan. Nondiskriminatif sebagaimana dimaksud pada ayat (1) dikecualikan bagi Sekolah yang secara khusus melayani atau menampung peserta didik dari kelompok gender atau agama tertentu, (Kementrian Pendidikan dan Kebudayaan, 2014). Sistem informasi adalah sebuah sistem di dalam suatu organisasi yang mengelola proses transaksi harian, proses manajerial untuk mendukung operasional dan kegiatan yang bersifat strategi dari suatu organisasi, yang akan digunakan untuk menyediakan laporan-laporan yang dibutuhkan pada pihak tertentu, (Hidayat, Muttaqin, \& Djamaludin, 2020).

Sistem Penerimaan Peserta Didik Baru Berbasis Web (Online) di SMK Muhammadiyah 7 Kedungpring Lamongan dapat menanggani dengan baik semua kegiatan pendaftaran calon siswa baru. Sistem dapat menyajikan hasil pendaftar calon peserta didik baru secara real time melalui media internet sehingga proses pendafataran tanpa harus datang langsung kesekolah. Adanya sistem yang dapat melakukan penginputan data, penyaringan data pendaftar, (Hidayat, Priambodo, \& Agustine, 2019).

Android adalah sebuah sistem operasi perangkat mobile berbasis linux yang mencakup semua sistem operasi, middleware 
dan aplikasi. Android menyediakan platform terbuka sehingga setiap para pengembang dapat berkreasi untuk menciptakan aplikasi sesuai dengan keinginan mereka. Awalnya, Google Inc. membeli Android Inc. yang merupakan system pendatang baru yang membuat piranti lunak untuk ponsel/ smartphone (Nugroho \& Arief, 2015).

Berdasarkan permasalahan diatas sistem aplikasi Website berbasis android merupakan salah satu solusi dan pilihan tepat yang kami tawarkan karena dapat dijadikan pilihan sebagai media informasi dan komunikasi yang ramah pada saat sekaran ini, disamping mudah pengoperasiannya hampir setiap orang atau keluarga pada saat sekarang memiliki perangkat smart phone. Perangkat ini dioperasikan sangat mudah sehingga dapat mempercepat proses penyampaian informasi kepada pihak luar yang membutuhkan.

\section{METODE PELAKSANAAN}

Metode pelaksanaan dalam PKM yaitu mengatasi permasalahan yang dihadapi dan telah disepakati dengan pihak mitra, adalah:

a. Melakukan pendekatan kepada Kepala Sekolah SD Mulia, untuk mensinergikan kegiatan-kegiatan yang akan dilakukan dalam program penerapan teknologi informasi berupa system aplikasi website berbasis android.

b. Metode pendekatan yang dilakukan adalah dengan melakukan Pelatihan memaitance bagi administrator dan penggunaan system aplikasi website SD Muhammadiyah 05 sehingga dapat meningkatkan kinerja organisasi, sehingga data informasi administrasi kegiatan kesiswaan dapat terkelolah dengan lebih baik.

c. Partisipasi mitra yaitu Admin dan staf IT SD Mulia Cilacap ditunjukkan dengan adanya dukungan dan kesanggupan untuk bekerjasama sebagai mitra dengan TIM pengusul dari Politeknik Negeri Cilacap. d. Rencana kegiatan yang terdiri dari persiapan, pelaksanaan, observasi, evaluasi, solusi perbaikan, pendampingan dan refleksi, yang terdiri dari:

1). Tahap Persiapan, proses yang dilakukan meliputi :

a) Survei, penentuan lokasi, sasaran yang ingin dicapai serta penentuan permasalahan yang dihadapi oleh mitra.

b) Evaluasi permasalahan yang dihadapi dan penentuan solusi yang ditawarkan kepada mitra.

c) Penyusunan materi tahap persiapan dan kelengkapan kegiatan

2) Tahap pelaksanaan meliputi :

a) Implementasi Aplikasi website SD Mulia Cilacap menggunakan metode waterfall (Chari \& Agrawal, 2018).

b) Pelatihan Teknis Penggunaan Aplikasi, yaitu :

- Pengetahuan standar tentang cara dan penggunaan smartphone sebagai alat.

- Pelatihan teknis penggunaan Aplikasi secara detail dan mencoba menginput masingmasin konten yang disediakan oleh menu website.

- Bagi admin diberi pelatihan cara mengelola website yang benar dari update informasi dan membuang informasi yang tidak terpakai.

Secara garis besar kegiatan program PKM di SD Mulia agar mudah pelaksanaannya dibuat sebuah alur/langkah. Tahapan setiap langkah harus dikerjakan dengan cermat agar hasilnya dapat maksimal sesuai dengan tujuan PKM. Untuk memastikan system yang dibuat sesuai yang dharapkan maka dilakukan pengujian menggunakan metode black box (Malaiya, 1995). Proses pelaksanaan PKM langkahnya dapat di lihat seperti pada gambar 1. 


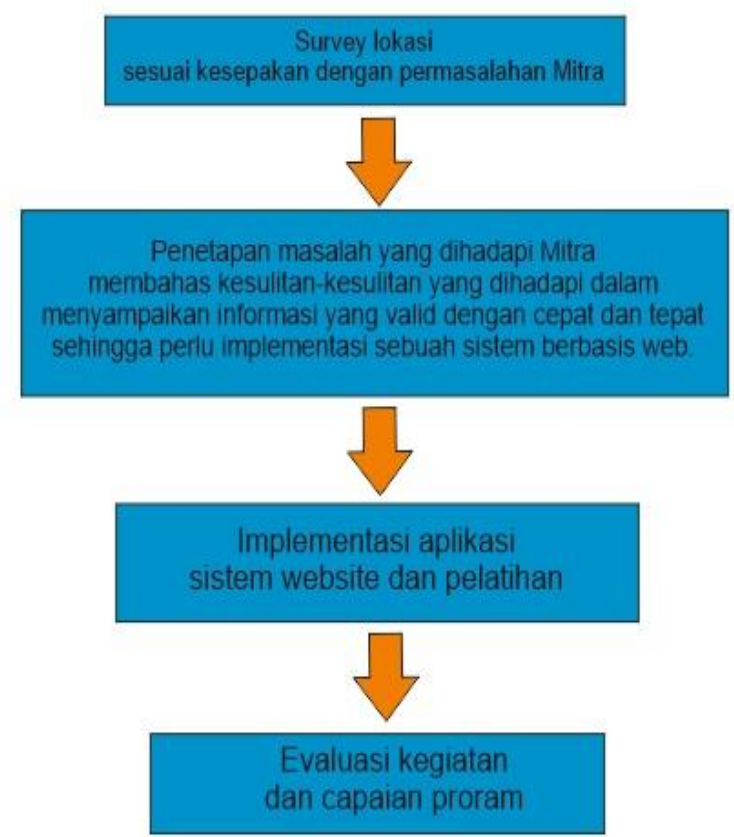

Gambar 1. Alur kegiatan PKM di SD Mulia

\section{HASIL DAN PEMBAHASAN}

Kegiatan pengabdian telah dilaksanakan pada tanggal 12 Agustus perkenalan dengan kepala sekolah SD Mulia dan 10 November tahun 2020. Kegiatan ini diikuti oleh kepala sekolah, guru dan pegawai administrasi SD Mulia. Jumlah peserta yang mengikuti pelatihan sebanyak 12 orang, Selama pelatihan berlangsung peserta sangat antusias dalam mengkuti pelatihan ini. Pengenalan system website dengan kepala sekolah seperti pada gambar 2.

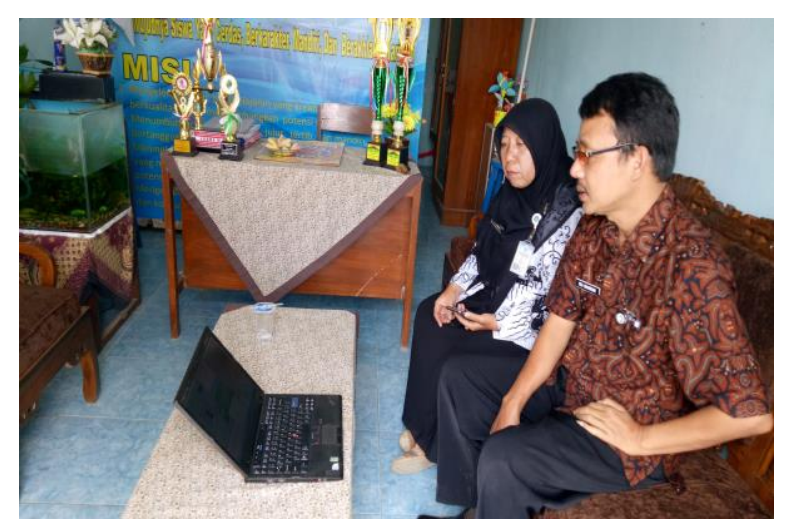

Gambar 2. Perkenalan system Website dengan kepala SD Mulia.

\subsection{Pelatihan Mengelola Webside SD Mulia}

Pelatihan cara mengelola isi konten dan meng uapdate berita berupa informasi yang terbaru sehingga informasi yang disampaikan di website selalu update. Dapat dilihat pada gambar 3.

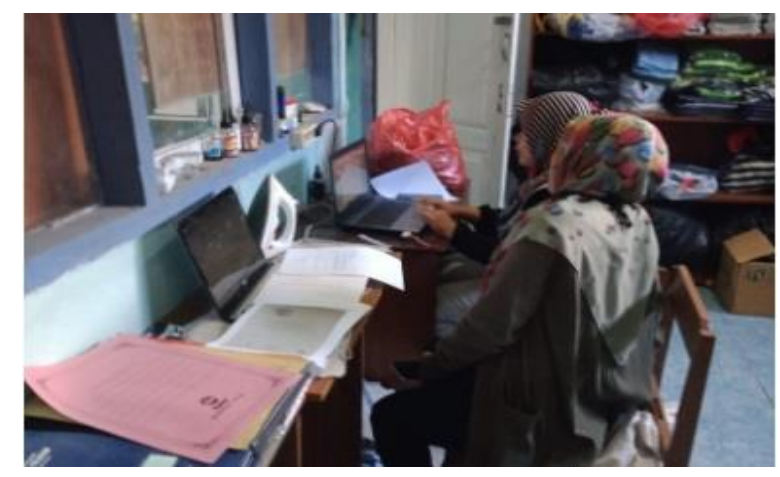

Gambar 3. Pelatihan menjadi administrator website SD Mulia

\subsection{Pelatihan Mengoperasikan Website SD Mulia}

Penggunaan Aplikasi akan diajari cara mengakses alamat website SD Mulia, lankah pertama membuat user name dan password sesuai dengan identitas peserta. Langkah berikutnya cara login masuk ke system, pelatihan sangat serius seperti pada gambar 4 .

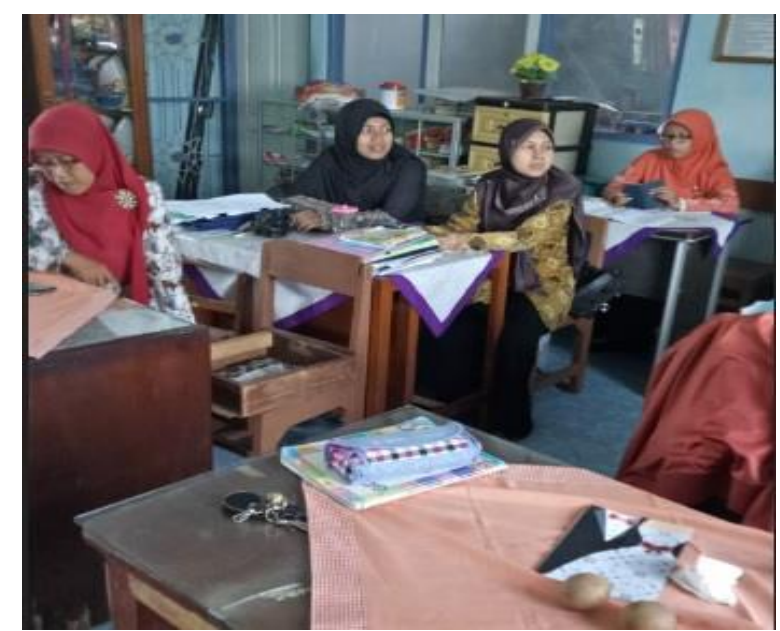

Gambar 4. Pelatihan penggunaan website dengan Guru dan Pegawai. 


\subsection{Cara Mengakses Website SD Mulia Menggunakan Smartphone}

Penggunaan Aplikasi akan dimulai dengan masuk ke alamat website SD Mulia yaitu: www.sdmuliacilacap.sch.id dengan syarat telah melakukan pendftaran dengan memasukan alamat email user dan mendaftarkan password terlebih dahulu. Malakukan login ke system menginput username dan password untuk keamanan Aplikasi maka diperlukan captcha agar sistem terhindar dari enjeksi robot. Apabila captcha tidak diisi dengan benar, maka akan tampil notifikasi bahwa nilai captcha yang diisi salah dan pengguna diharuskan mengisi data captcha yang benar, jika sudah benar maka akan tampil seperti pada seperti pada gambar 5 .

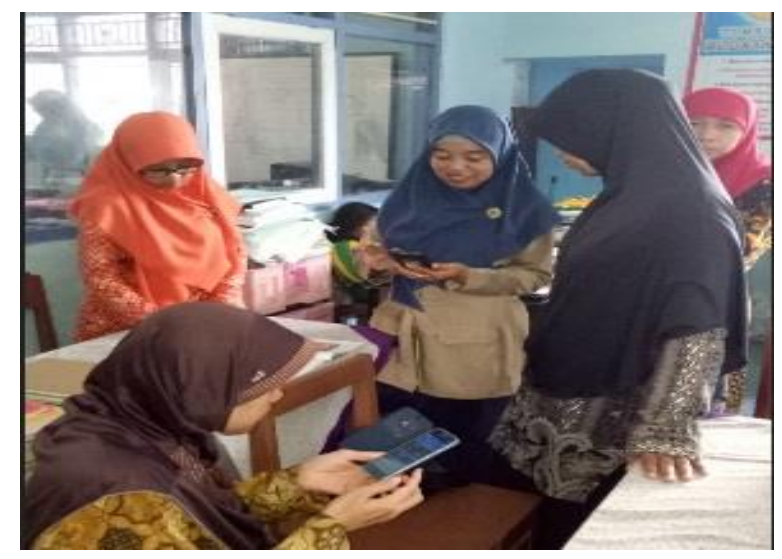

Gambar 5. Halaman menu website SD Mulia

Penggunaan Aplikasi akan dimulai dengan membuka system, dengan syarat admin terlebih dahulu malakukan login ke system dengan menginput username dan password untuk keamanan Aplikasi maka diperlukan captcha agar sistem terhindar dari enjeksi robot. Apabila captcha tidak diisi dengan benar, maka akan tampil notifikasi bahwa nilai captcha yang diisi salah dan pengguna diharuskan mengisi data captcha yang benar, jika sudah benar maka akan tampil seperti pada beberapa menu vitur-vitur sebagai berikut:

\subsection{Menu Utama Halaman Website}

Menu utama halaman website yang dimulai mengakses menu login. Memasukan username dan password maka akan tampil menu yang menampilkan sub menu setiap konten seperti pada gambar 6 .

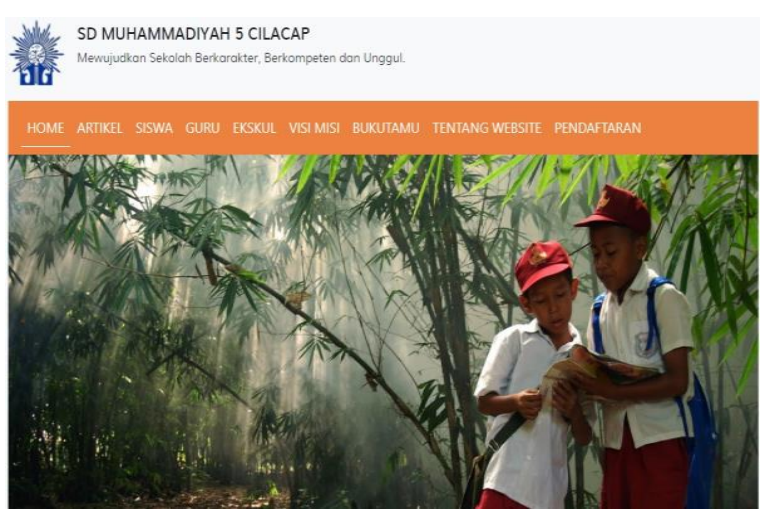

Gambar 6. Halaman menu website SD Mulia

\subsection{Menu Pendaftaran Siswa Baru}

Menu ini dapat diakses oleh setiap user yang telah mendaftar sebagai anggota. Para orang tua yang akan mendaftarkan anaknya menjadi colon siswa dapat mengisi formulir pendaftaran seperti pada gambar 7 .

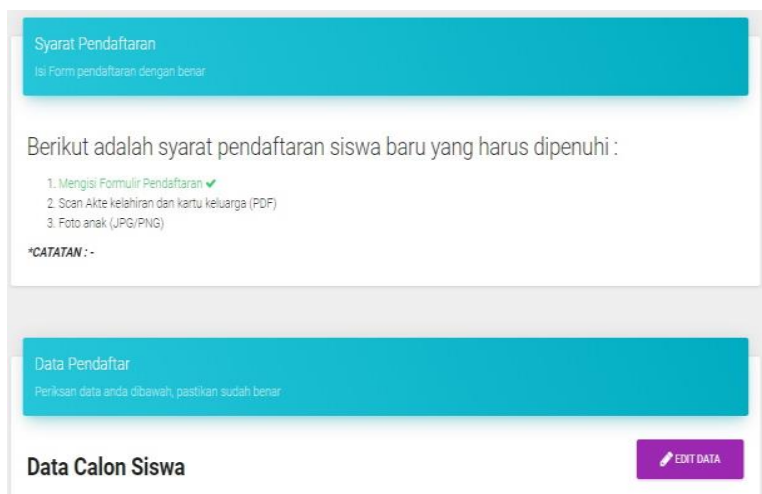

Gambar 7. Halaman konten data calon siswa baru

\subsection{Konten Menu Pendaftara Siswa Baru}

Halaman menu pendafaran siswa baru terdiri beberapa sub menu. Masing-masing menu harus diisi dengan data calon siswa yang benar. Seperti pada gambar 8 . 


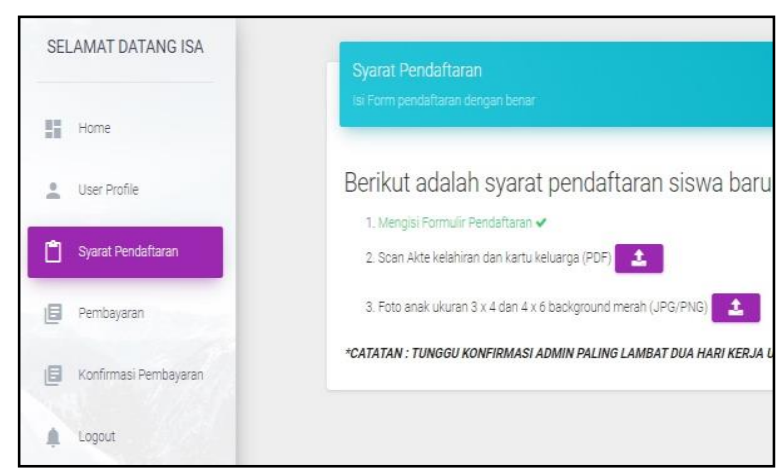

Gambar 8. Menu Pendaftaran Siswa Baru

\subsection{Menu Admin}

Menu admin berfungsi untuk mengelola semua aktifitas opererasional website. Baik dan buruknya pengelolaan sebuah website tergantung dari kreatifitas seorang admin yang dipercaya. Seperti pada gambar 9.

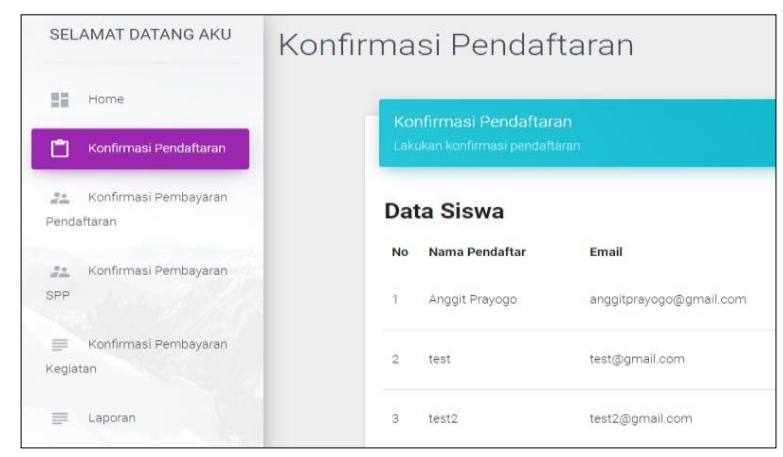

Gambar 9. Menu Admin website SD Mulia

\subsection{Pelatihan Terakhir PKM}

Pertemuan terakhir kegiatan PKM untuk menyamakan kebutuhan konten website SD Mulia. Isi konten website disesuaikan dengan kebutuhan manajemen sekolah, setelah pada tahap implementasi ada tambahan isi konten sehingga ada beberapa menu yang harus ditambahkan untuk disesuaikan dengan kebutuhan operasional menejemen sekolah. Pertemuan yang berlangsung dapat dilihat pada gambar 10.

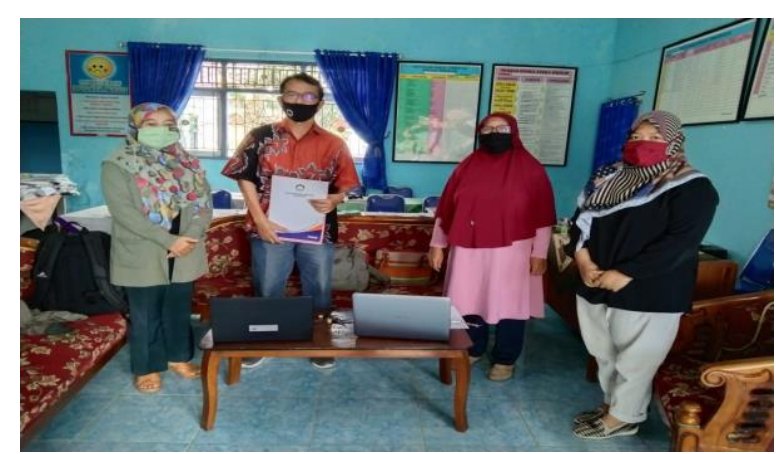

Gambar 10. Pertemuan terahir PKM

\section{DATA PESERTA PELATIHAN}

Data peserta pelatihan pengoperasian website SD Mulia dan operasional Administrator. Pelatihan diikuti oleh beberapa guru dan staf administrator sekolah, seperti pada Tabel 1.

Tabel 1. Peserta Pelatihan

\begin{tabular}{clc}
\hline No & Peserta Pelatihan & Jumlah \\
\hline 1 & Guru & 8 \\
2 & Orang Tua Siswa & 2 \\
3 & Tenaga kependidikan & 2 \\
4 & Siswa & 0 \\
\hline
\end{tabular}

\section{KESIMPULAN}

Program Pengabdian Kepada Masyarakat telah selesai dilaksanakan, Pelatihan Aplikasi website SD Mulia berjalan dengan baik dan selama pelatihan berlangsung peserta sangat antusias untuk mengikuti. Pihak sekolah bersedia untuk menerima system yang telah di buat ini sebagai pengembangan sistem yang akan diimplementasikan pada PPDB setiap tahun dan pihak sekolah juga merasa senang karena dengan adanya aplikasi ini sehingga berharap nantinya dapat membantu operasional sekolah terutama pada saat berlangsungnya program PPDB. Semua informasi yang ada di SD Mulia akan bisa di publikasi dengan mudah, transparan, cepat dan akurat. 


\section{UCAPAN TERIMA KASIH}

Terima Kasih tim Pelaksana PKM ucapkan kepada P3M Politeknik Negeri Cilacap yang telah memfasilitasi kegiatan Pengabdian Kepada Masyarakat yang dilaksanakan oleh Dosen Prodi Teknik Informatika, sehingga kegiatan ini dapat terlaksana dengan baik. Selanjutnya Tim PKM Politeknik Negeri Cilacap mengucapkan banyak terimakasih kepada Pihak SD Muhammadiyah 05 Cilacap yang telah bersedia menjadi mitra Pengabdian ini dan bersedia meluangkan waktu untuk mengkuti kegiatan pelatihan sampai ahkir kegiatan.

\section{DAFTAR PUSTAKA}

Chari, K., \& Agrawal, M. (2018). Impact of incorrect and new requirements on waterfall software project outcomes. Empirical Software Engineering, 23(1), 165-185. https://doi.org/10.1007/s10664017-9506-4

Hidayat, T., Muttaqin, M., \& Djamaludin, D. (2020). Sistem Informasi Penerimaan Peserta Didik Baru Online Berbasis Website di Yayasan Pendidikan Arya Jaya Sentika. Komputika: Jurnal Sistem Komputer, 9(1), 7-14. https://doi.org/10.34010/komputika.v9i1. 2750

Hidayat, T., Priambodo, T. A., \& Agustine, D. (2019). Perancangan Website Sistem Informasi Akademik Sekolah Dasar ( Studi Kasus : SDS Arya Jaya Sentika Tigaraksa Kabupaten Tangerang ). SATIN - Sains Dan Teknologi Informasi, 4(2), 1. https://doi.org/10.33372/stn.v4i2.394

Kementrian Pendidikan dan Kebudayaan, republik indonesia. (2014). Penerimaan Peserta Didik Baru.

Malaiya, Y. K. (1995). Antirandom testing: getting the most out of black-box testing. Proceedings of the International Symposium on Software Reliability Engineering, ISSRE, 86-95. https://doi.org/10.1109/issre.1995.497647 Nugroho, A., \& Arief, H. (2015). Perancangan Sistem Informasi Penerimaan Siswa Baru Berbasis Web (Studi Kasus Di SMA Nusaputera Semarang. Jurnal Teknologi
Informasi Dan Komunikasi, 6(2), 1-10. Wanti, L. P., \& Tripustikasari, E. (2019). Pelatihan Komputer Dasar Bagi Kader PKK dan Posyandu Di Desa Patikraja. Madani : Indonesian Journal of Civil Society, 1(1), 17-23. https://doi.org/10.35970/madani.v1i1.22 